\title{
Correction to: Dissection of two quantitative trait loci with pleiotropic effects on plant height and spike length linked in coupling phase on the short arm of chromosome 2D of common wheat (Triticum aestivum L.)
}

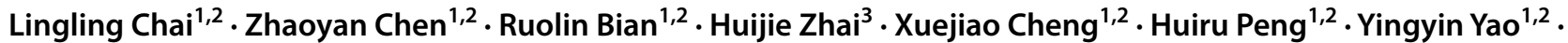 \\ Zhaorong $\mathrm{Hu}^{1,2} \cdot$ Mingming Xin ${ }^{1,2}$. Weilong Guo ${ }^{1,2}$. Qixin Sun ${ }^{1,2}$. Aiju Zhao ${ }^{4}$. Zhongfu Ni ${ }^{1,2}$
}

Published online: 24 September 2019

(c) Springer-Verlag GmbH Germany, part of Springer Nature 2019

\section{Correction to: \\ Theoretical and Applied Genetics (2019) 132:1815-1831 \\ https://doi.org/10.1007/s00122-019-03318-z}

Unfortunately, the history details and the name of the communicating editor were incorrectly published in the original publication. The complete correct details are given below.

Received: 30 May 2018/Accepted: 1 September 2018/ Published online: 26 March 2019

Communicated by Evans Lagudah.

The original article can be found online at https://doi.org/10.1007/ s00122-019-03318-z.

Aiju Zhao

zhaoaiju81@126.com

$\triangle$ Zhongfu Ni

nizf@cau.edu.cn

1 State Key Laboratory for Agrobiotechnology/Key Laboratory of Crop Heterosis and Utilization, the Ministry of Education/Key Laboratory of Crop Genetic Improvement, Beijing Municipality, China Agricultural University, Beijing 100193, China

2 National Plant Gene Research Centre, Beijing 100193, China

3 College of Agronomy, Henan Agricultural University, Zhengzhou 450002, China

4 Institute of Cereal and Oil Crops, Hebei Academy of Agriculture/Forestry Sciences, Hebei Crop Genetic Breeding Laboratory, Shijiazhuang 050035, China
Publisher's Note Springer Nature remains neutral with regard to jurisdictional claims in published maps and institutional affiliations. 